\title{
Title: Global ecosystem thresholds driven by aridity
}

Authors: Miguel Berdugo ${ }^{1,2^{*}}$, Manuel Delgado-Baquerizo ${ }^{1}$, Santiago Soliveres ${ }^{1,3}$, Rocío Hernández-Clemente ${ }^{4}$, Yanchuang Zhao ${ }^{5,6}$, Juan J. Gaitán ${ }^{7,8,9}$, Nicolas Gross ${ }^{10}$, Hugo Saiz ${ }^{11}$, Vincent Maire $^{12}$, Anika Lehmann ${ }^{13,14}$, Matthias C. Rillig ${ }^{13,14}$, Ricard V. Solé ${ }^{2,15}$ and Fernando T. Maestre ${ }^{1,3}$.

\section{Affiliations:}

${ }^{1}$ Instituto Multidisciplinar para el Estudio del Medio “Ramón Margalef”, Universidad de Alicante, Carretera de San Vicente del Raspeig s/n, 03690 San Vicente del Raspeig, Alicante, Spain.

${ }^{2}$ Institut de Biología Evolutiva, Barcelona, Spain.

${ }^{3}$ Departamento de Ecología, Universidad de Alicante, Carretera de San Vicente del Raspeig s/n, 03690 San Vicente del Raspeig, Alicante, Spain

${ }^{4}$ Swansea University, Department of Geography, Singleton Park, Swansea, SA2 8PP, UK.

${ }^{5}$ College of Information Science and Engineering, Henan University of Technology, 450001, 15 Zhengzhou, China.

${ }^{6}$ Key Laboratory of Digital Earth Science, Institute of Remote Sensing and Digital Earth, Chinese Academy of Sciences, 100094 Beijing, China.

${ }^{7}$ Instituto de Suelos, CIRN, INTA, Nicolas Repetto y de los Reseros Sin Número, Hurlingham, Buenos Aires, Argentina.

${ }^{8}$ Departamento de Tecnología, Universidad Nacional de Luján, 6700 Luján, Argentina. 
${ }^{9}$ National Research Council of Argentina (CONICET), Buenos Aires, Argentina.

${ }^{10}$ UCA, INRA, VetAgro Sup, UMR 0874 Ecosystème Prairial, 63000 Clermont-Ferrand, France.

${ }^{11}$ Institute of Plant Sciences, University of Bern. Altenbergrain 21, 3013 Bern, Switzwerland.

${ }^{12}$ Département des sciences de l'environnement, Université du Québec à Trois Rivières, Trois Rivières, Québec, Canada.

${ }^{13}$ Institute of Biology, Freie Universität Berlin, 14195 Berlin, Germany.

${ }^{14}$ Berlin-Brandenburg Institute of Advanced Biodiversity Research (BBIB), 14195 Berlin, Germany.

${ }^{15}$ Santa Fe Institute, Santa Fe, NM, USA.

10

*Correspondence to: mglberdugo@gmail.com. 


\begin{abstract}
:
Aridity, increasing worldwide due to climate change, affects the structure and functioning of dryland ecosystems. Whether aridification leads to gradual (vs. abrupt) and systemic (vs. specific) ecosystem changes is largely unknown. We investigated how 20 structural and functional 5 ecosystem attributes respond to aridity in global drylands. Aridification led to systemic and abrupt changes in multiple ecosystem attributes. These changes occurred sequentially in three phases characterized by abrupt decays in plant productivity, soil fertility and plant cover/richness at aridity values of $0.54,0.7$ and 0.8 , respectively. Over $20 \%$ of the terrestrial surface will cross one/several of these thresholds by 2100 , which calls for immediate actions to minimize the negative impacts

10 of aridification on essential ecosystem services for the more than 2.5 billion people living in drylands.
\end{abstract}

One Sentence Summary: Increasing aridity promotes sequential, systemic and abrupt thresholds in dryland ecosystems.

15 


\section{Main Text:}

Drylands, areas where rainfall is below $65 \%$ of evaporative demand ( 1 ), cover $\sim 45 \%$ of emerged lands (2) and are especially vulnerable to climate change and land degradation (3, 4). Increasing aridity $(1-$ [precipitation/potential evapotranspiration]) is major imprint of climate change in global drylands (3) and will impact multiple ecosystem structural and functional attributes (e.g., nutrient cycling, plant productivity, and microbial communities, 5). However, it remains to be elucidated whether these impacts will be gradual or abrupt $(5-7)$. Recent research $(1,8)$ has shown abrupt losses of soil nutrient availability in the transition between semiarid and arid ecosystems (aridity levels $\sim 0.7$ ). Likewise, modelling studies have predicted the existence of single thresholds in particular structural attributes, such as vegetation cover or spatial pattern, along climatic gradients (9). Whether non-linear responses of ecosystem attributes to increases in aridity are the norm rather than the exception, and whether these responses exhibit single or multiple thresholds remain largely unknown. Ecosystem attributes are highly interconnected $(5,10,11)$; therefore, changes in a given attribute induced by increases in aridity may trigger sequential changes in others

15 that depend on it but work at different spatial (12) or temporal (10) scales. If these interconnected changes are abrupt, this could potentially result in a series of aridity thresholds affecting multiple ecosystem attributes. For instance, increasing aridity may cause a rapid shift in the composition of soil microbes, which in turn may trigger changes in plant-microbial interactions that later lead to changes in nutrient cycling and plant community composition (13). Therefore, understanding whether the inter-related responses of multiple ecosystem attributes to increasing aridity cancel each other out, buffering the negative impacts of climate change, or if they are characterized by one or multiple sequential ecosystemic thresholds that amplify them is crucial for improving forecasts of ecosystem responses to climate change. This information is also critical to depict 
vulnerabilities in global drylands and to forecast the provision of ecosystem services, maintaining the more than 2.8 billion people that inhabit these areas worldwide, particularly in developing countries (4).

Herein we evaluated whether: (i) multiple ecosystem structural and functional attributes exhibit linear or non-linear responses to increases in aridity; and (ii) these responses are driven by the existence of single or multiple thresholds in global drylands. To do so, we compiled $>50,000$ data points that spanned multiple biological organization levels (from individuals to ecosystems) and global datasets, including standardized laboratory measurements, field surveys, map interpolations and remote sensing information (Table S1, Fig. S1). We evaluated 20 functional and structural ecosystem attributes, including physical (e.g., albedo, soil texture, precipitation variability), biological (e.g., plant cover, richness, functional traits, microbial communities) and chemical (e.g., soil organic carbon, leaf nitrogen) variables. These attributes are strongly related to the ability of drylands to provide essential ecosystem services such as climate regulation, nutrient cycling and livestock production (the most extensive land use in global drylands, 6), and largely determine 15 their responses to climate change and desertification drivers (5). We also studied variables related to plant-soil (e.g., fertility islands associated with the presence of plant canopies 14), plant-climate (e.g., plant resistance to climatic variability) and plant-plant (e.g., spatial networks) interactions, which underpin many ecosystem processes in terrestrial ecosystems $(11,15$; see ref. 16 for further rationale).

20 All the ecosystem functional and structural attributes evaluated responded in a non-linear manner to increases in aridity (Table S2). In other words, once an aridity level is reached, small increases in aridity led to drastic changes in the value of the attribute (Fig. S2) or modified its relationship with aridity (changing slope, Fig. S3). Whereas all responses to aridity observed fitted better to a 
non-linear or abrupt change (i.e., discontinuous changes sensu ref. 17) than to a linear monotonic model (Table S2), for some variables the variance explained was relatively low. This suggests that other environmental or human-related factors, such as topography or land use, may also interact with aridity to determine observed non-linear changes, which provides scope for actions aimed at minimizing these drastic shifts.

Contrary to what is commonly assumed by theoretical approaches (9), observed responses of ecosystem attributes to increases in aridity followed a sequential series of thresholds. The presence of multiple thresholds has been conceptualized regarding ecosystem degradation (18), but have not yet received empirical and quantitative support. Thus, our results suggest that the response of 10 drylands to aridity can be organized in three phases characterized by concurring non-linear or abrupt ecosystem shifts (Fig. 1). Observed ecosystem changes with increases in aridity start with a "vegetation decline phase" characterized by a sharp reduction in vegetation productivity (as measured using remote sensing, see 16) at aridity levels $\geq 0.54$ (Fig. 2A). This reduction in vegetation productivity is consistent with observed decreases in light-saturated leaf photosynthetic 15 activity measured in situ on 809 plant species across the world (Fig. S4). Plants typically reduce their leaf area to adapt to dry conditions (19), often increasing their leaf-mass/area ratio, nitrogen content and relative photosynthetic capacity per unit of leaf area (20). However, our results suggest that such leaf-adaptation to drought may compromise raw plant photosynthesis and productivity, leading to a sharp decline in these key ecosystem attributes at aridity levels around 0.54 .

20 As aridity continues to increase, we identified a "soil disruption" phase characterized by changes in multiple ecosystem structural and functional attributes under aridity levels higher than 0.7. These include abrupt declines in soil variables such as organic carbon -a key determinant of soil fertility-, total nitrogen and clay contents, stability of aggregates and relative abundance of fungal 
functional groups (Fig. 2C; Fig. S5). Observed reductions in soil nutrients could be associated with decreased plant-derived organic inputs into the soil, which are driven by reductions in plant productivity observed during the "vegetation decline" phase and by drastic reductions in leaf nitrogen content occurring at aridity $\sim 0.65$ (Fig. $2 \mathrm{~B}$ ). This notion is further supported by the sharp decline in the positive effect of plant canopies (regarding bare soil areas) on soil organic carbon (Fig. 2D), and by the reduction in the relative abundance of saprotrophic fungi (Fig. S5I), which are key drivers of the formation of "fertility islands" in drylands (14). We speculate that this net reduction in the quantity and quality of plant carbon inputs into the soil may occur as a consequence of the excessive costs needed for extracting water and nutrients to keep a positive carbon gain under increasingly arid conditions (21). Our results further show abrupt declines in the relative abundance of ectomycorrhizal fungi at this aridity level (Fig. S5I), which have also been linked with abrupt changes in plant community composition and soil biogeochemical cycles (13). Other changes observed beyond the 0.7 aridity threshold include a decline in the frequency of positive plant-plant interactions (Fig. S5H and ref. 22), for which soil amelioration is a 15 fundamental component $(9,23)$. During this "soil disruption" phase, vegetation shifts from grasslands and savannahs to shrublands (Fig. S5D), which are better adapted to nutrient-poor and sandy soils $(23,24)$. We also found a steep decrease in the overall sensitivity of vegetation to climatic fluctuations (25) (Fig. S5A), which might be associated to the deeper root systems commonly found in shrubs, which make them less sensitive to seasonal droughts (24). The shift to 20 shrub-dominated vegetation observed adds to other transitions identified under wetter climates, such as those occurring between forests and savannas (26) or C3- and C4-dominant grasslands (27), and provides novel and relevant information to understand how climate change may affect dominant vegetation, and associated soil properties, in large areas of our planet. 
Finally, we detected an "ecosystem breakdown" phase, characterized by extreme reductions in plant cover and exponential increases in albedo beyond aridity values of 0.8 (Fig. 2E; Fig. S6C). Once this aridity level is crossed, most plant species may no longer survive shortages in water and nutrient availability. Accordingly, we observed a strong decline in plant species richness at this stage (Fig. 2F) consistent with a major turnover in species reported in other studies (28). These changes are associated with drastic increases in specific leaf area, a trait linked to plant resource use and litter decomposition (Fig. S6B), and leaf photosynthetic rates (see Fig. S4). The observed changes could be related to a physiological limit for the existence of stress-tolerant strategies and evergreen vegetation at aridity levels $>0.8$, as this vegetation is replaced by stress-avoidant summer deciduous shrub species that may benefit most from the sparse and unpredictable rain events characterizing these environments $(21,29)$ (Fig. S6D). We also found a sudden increase in the relative abundance of fungal animal pathogens in the soil (Fig. S6A), which adds to the negative effects of reducing plant cover/biomass by potentially increasing the incidence of important fungal diseases.

15 According to current climatic forecasts (IPCC's RCP8.5 scenario, 3), up to $22 \%$ of terrestrial surface (28.6\% of current dryland area) will cross one or more of the three phases identified by 2100 (Fig. 3, see also Fig. S7). Therefore, according to our space-for-time substitution approach, these regions (Fig. 3) are at high risk of rapid declines in ecosystem functional and structural attributes, key to maintaining their capacity to provide essential ecosystem services. Areas

20 expected to cross the 0.8 aridity threshold are particularly sensitive and will undergo massive vegetation collapse and species loss. Increases in albedo associated with these vegetation changes, however, may affect the energy balance of Earth's surface and partially buffer global warming (30). Nevertheless, we must remember that such changes would render these areas 
unable to sustain current animal and human populations, with fundamental and negative consequences for human well-being globally.

Our results, based on analyzing the most comprehensive empirical evidence available so far, show that the responses of multiple functional and structural ecosystem attributes to increases in aridity follow a series of sequential thresholds. Our work goes beyond current knowledge by identifying, for the first time, three phases of abrupt ecosystem changes characterized by consecutive aridity thresholds. Along with recent studies dealing with multiscale regime shifts (12), our study provides a well-defined framework for sequential shifts that can inspire a new generation of multiscale models to explore ecosystem responses to climate change. Our findings also set the stage for future studies exploring temporal changes in the ecosystem variables investigated, particularly in areas likely to cross the aridity thresholds identified in the future, and put the focus on identifying potential catastrophic shifts and early warning indicators for them. Finally, the framework introduced here can be used to identify those attributes for which the responses to aridity are more sensitive to buffering, and for establishing effective adaptation and mitigation actions aimed at 15 preserving the capacity of drylands to supply essential ecosystem services needed to sustain a growing human population. 


\section{Acknowledgments:}

We used data from LP DAAC, USGS/Earth Resources Observation and Science (EOSDIS), maintained by NASA (see refs: 39, 46, 50, 59). We also thank Rebecca Rongstock and all members of the EPES-BIOCOM network and the Maestre lab for their contribution to the global dryland survey used, Samantha Travers for useful comments in previous versions of the manuscript, and Ángela Berdugo for designing part of the artwork of Figure 1.

Funding: This research was supported by the European Research Council (ERC Grant Agreements 242658 [BIOCOM] and 647038 [BIODESERT] awareded to FTM). MB acknowledges support from a Juan de la Cierva- Formación grant from Spanish Ministry of Economy and Competitiveness (FJCI-2018-036520-I). FTM acknowledges support from Generalitat Valenciana (CIDEGENT/2018/041), from the Alexander von Humboldt Foundation and from the Synthesis Centre for Biodiversity Sciences (sDiv) of the German Centre for Integrative Biodiversity Research (iDiv). MDB acknowledges support from the Marie Sklodowska-Curie Actions of the Horizon 2020 Framework Program H2020-MSCA-IF-2016 under REA grant agreement $\mathrm{n}^{\circ}$ 702057. SS was supported by the Spanish Government under a Ramón y Cajal contract (RYC-2016- 20604). NG was supported by the AgreenSkills+ fellowship programme, which has received funding from the EU's Seventh Framework Programme under grant agreement $N^{\circ}$ FP7-609398 (AgreenSkills+ contract). VM was supported by the FRQNT2017-NC-198009 and NSERC-Discovery-2016-05716 grants. HS is supported by a Juan de la

20 Cierva-Formación grant from Spanish Ministry of Economy and Competitiveness (FJCI-201526782). AL and MCR were supported by ERC Advanced Grant - Gradual Change (grant number: 694368) and Deutsche Forschungsgesellschaft grant (grant number: RI 1815/16-1). YZ was 
supported by the Strategic Priority Research Program of the Chinese Academy of Sciences (Grant No. XDA19030500).

Author contributions: MB designed the study and performed statistical analysis on data extracted and pre-analyzed by FTM, HS, JJG, RHC, YZ, MDB, NG, VM, AL and MCR. MB wrote the manuscript and all the authors, especially FTM, SS, MDB and NG, contributed significantly to further editions and revising of the text.

Competing interests: Authors declare no competing interests.

Data and materials availability: The $\mathrm{R}$ codes used as well as the data extracted in this study are available from ref. 124 .

Supplementary Materials:

Materials and Methods

Supplementary text

Figures S1-S14

Tables S1-S3

15

References (31-124) 


\section{Figures:}
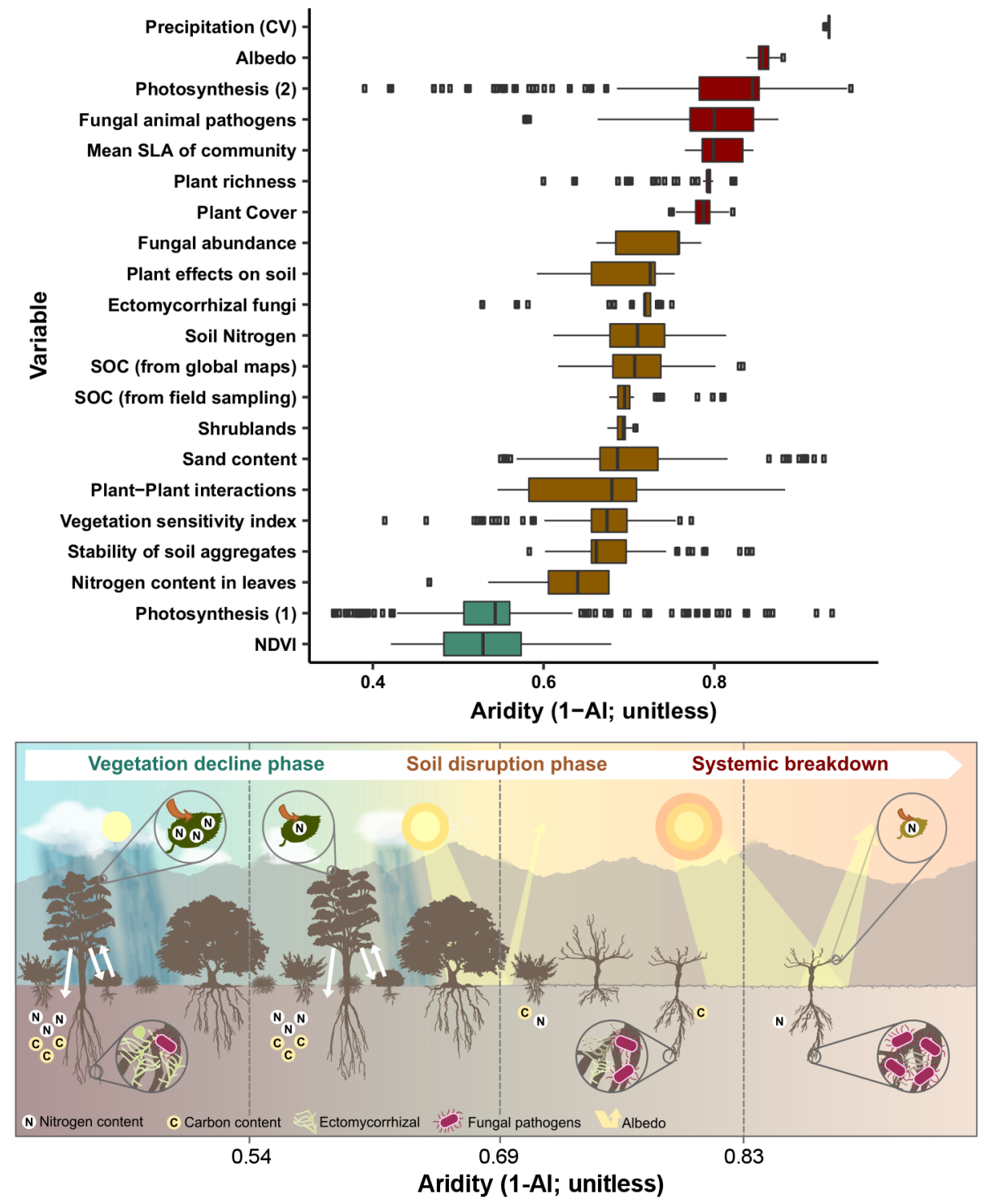

Fig. 1. Sequence of abrupt responses in global drylands as aridity increases. Top: values of the 21 aridity thresholds identified, with their Bootstrapped confidence intervals. Each color identifies a homogeneous set of variables that do not overlap others and define phases of abrupt shifts. SOC = soil organic carbon, NDVI: Normalized difference vegetation index. Bottom: a schematic representation of ecosystem changes associated with the crossing of the three phases we identified. The first threshold, related to a decay in vegetation productivity and photosynthetic 
activity, occurs when crossing an aridity level around 0.55 . At aridity levels $\sim 0.7$, sharp declines in soil fertility, plant nitrogen content and biotic (plant-soil, plant-plant) interactions, and drastic compositional changes in plant and soil microbial communities are observed. Finally, drastic reductions in plant cover, increases in soil albedo and shifts in leaf traits towards stress-avoidance 5 were detected when aridity level $\sim 0.8$. Ilustration by DharmaBeren Studio (www.dharmaberen.com). 

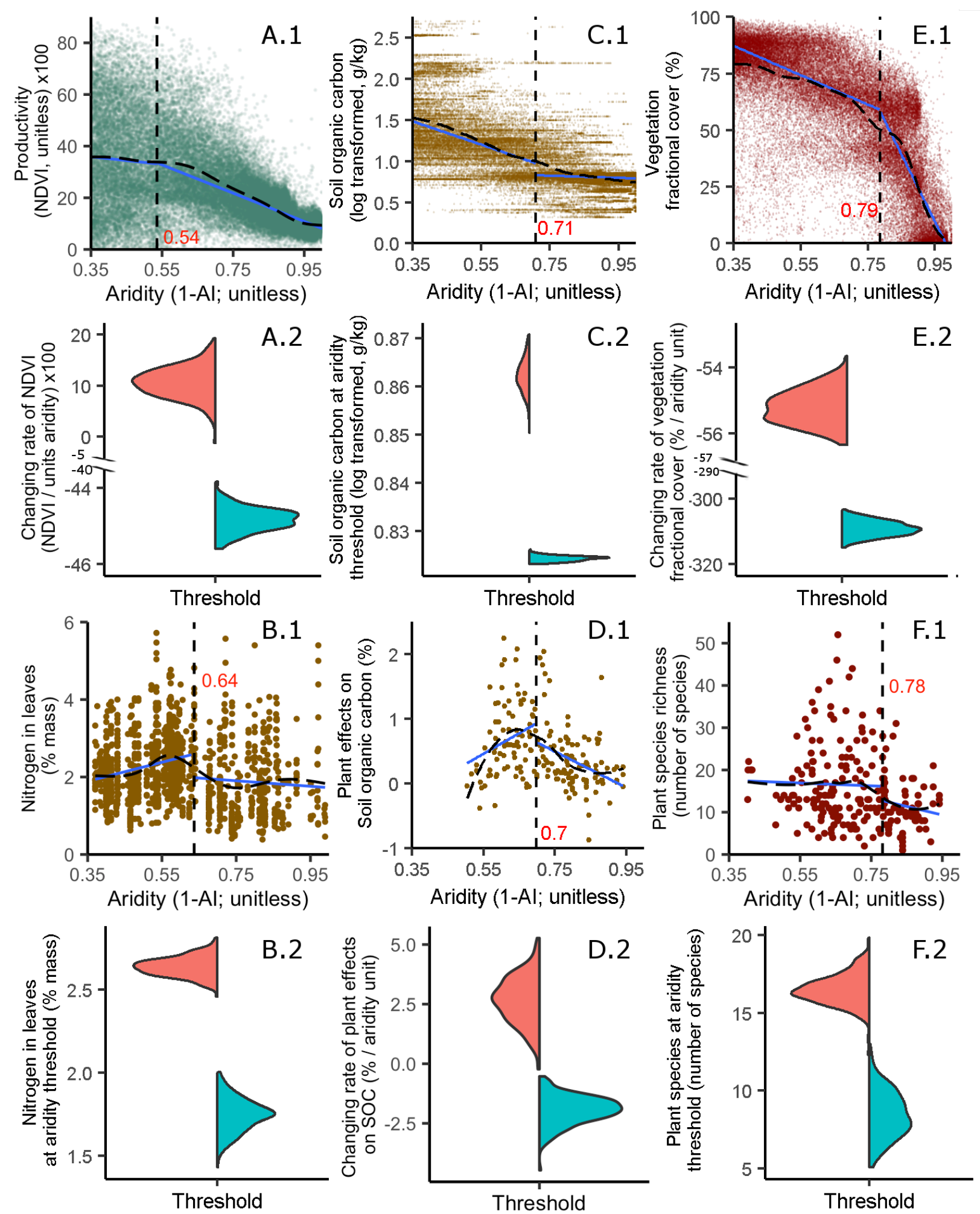

Fig. 2. Non-linear responses of multiple ecosystem attributes to aridity. Examples of aridity thresholds observed for NDVI (normalized difference vegetation index; A), leaf nitrogen content 
(B), soil organic carbon (C), plant effects on soil organic carbon (D), vegetation cover (E) and plant species richness (F). 1: Black-dashed and blue (solid) lines represent the smoothed trend fitted by a GAM model and the linear fits at both sides of each threshold, respectively. Inset numbers in red and the vertical dashed lines describe the aridity threshold identified. 2: Violin diagrams show bootstrapped slopes (A, D and E) or values of the predicted fitted trend at the threshold (B, C, and F) of the two regressions existing at each side of the threshold (red: before the threshold; blue, after the threshold).

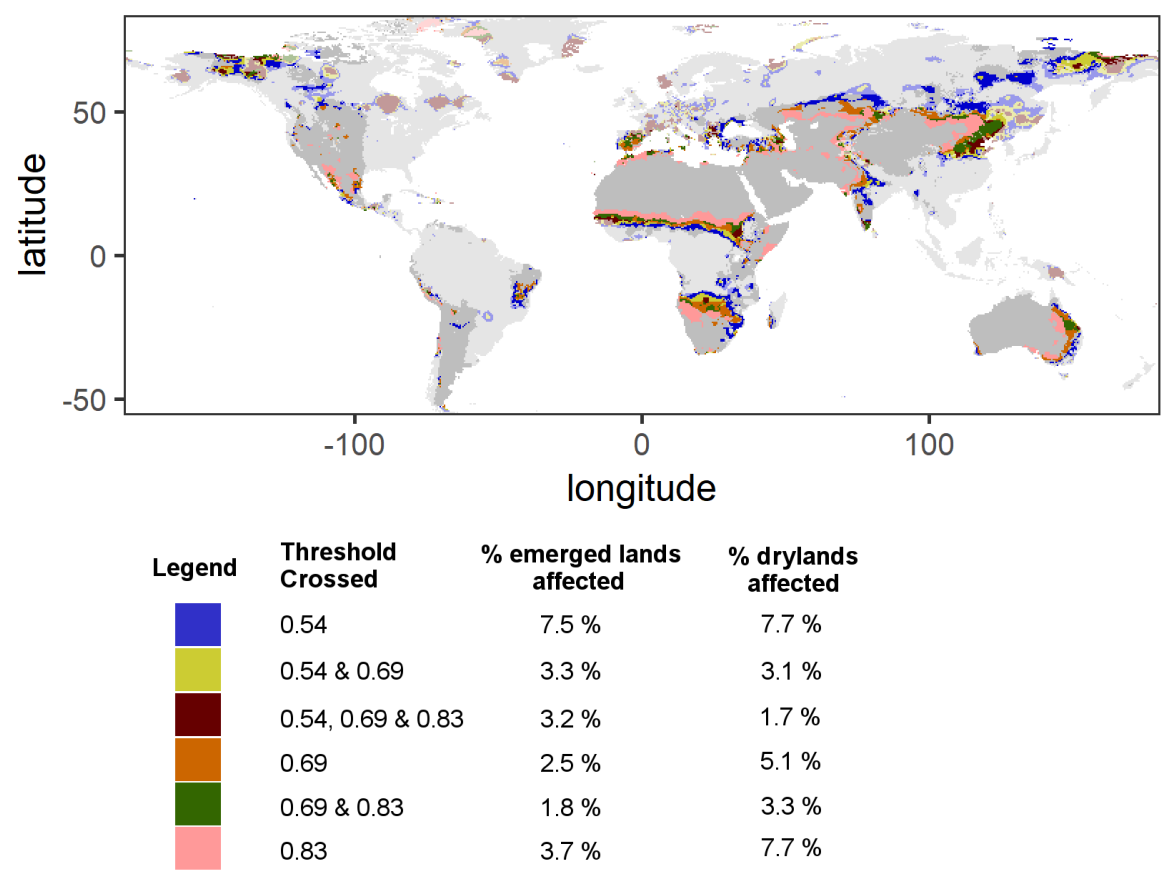

Fig. 3. Map of climate change vulnerability in global drylands. This map includes areas that will cross each (or several) of the phases described according to the aridity predicted for 2100 by the IPCC rcp8.5 scenario (i.e., under the assumption of sustained increase in $\mathrm{CO}_{2}$ emissions). Transparent areas are outside the range used for the data in this study (i.e. areas that are not drylands today, see (16) for further details). 


\section{References and Notes (full reference list):}

1. M. Delgado-Baquerizo et al., Decoupling of soil nutrient cycles as a function of aridity in global drylands. Nature. 502, 672-676 (2013).

2. R. Prăvălie, Drylands extent and environmental issues. A global approach. Earth-Science Rev. 161, 259-278 (2016).

3. J. Huang, H. Yu, X. Guan, G. Wang, R. Guo, Accelerated dryland expansion under climate change. Nat. Clim. Chang. 6, 166-171 (2015).

4. N. J. Middleton, T. Sternberg, Climate hazards in drylands: A review. Earth-Science Rev. 126, 48-57 (2013).

5. F. T. F. T. Maestre et al., Structure and Functioning of Dryland Ecosystems in a Changing World. Annu. Rev. Ecol. Evol. Syst. 47, 215-237 (2016).

6. M. Cherlet et al., World Atlas of Desertification (Publication Offise of the European Union, Luxembourg, ed. 3rd, 2018).

7. United Nations Department of Economic and Social Affairs, "The Sustainable Development Goals Report 2017” (New York, 2017), , doi:https://doi.org/https://doi.org/10.18356/4d038e1e-en.

8. M. Berdugo, S. Kéfi, S. Soliveres, F. T. F. T. Maestre, Plant spatial patterns identify alternative ecosystem multifunctionality states in global drylands. Nat. Ecol. Evol. 1, 3 (2017).

20 9. S. Kéfi, M. Rietkerk, M. van Baalen, M. Loreau, Local facilitation, bistability and transitions in arid ecosystems. Theor. Popul. Biol. 71, 367-379 (2007). 
10. J. F. Reynolds et al., Global desertification: building a science for dryland development. Science 316, 847-851 (2007).

11. W. H. Schlesinger et al., Biological feedbacks in global desertification. Science 247, 10431048 (1990).

12. J. C. Rocha, G. Peterson, Ö. Bodin, S. Levin, Cascading regime shifts within and across scales. Science 362, 1379-1383 (2018).

13. M. Lu, L. O. Hedin, Global plant-symbiont organization and emergence of biogeochemical cycles resolved by evolution-based trait modelling. Nat. Ecol. Evol. 3, 239-250 (2019).

14. R. Ochoa-Hueso et al., Soil fungal abundance and plant functional traits drive fertile island formation in global drylands. J. Ecol. 106, 242-253 (2018).

15. L. Turnbull et al., Understanding the role of ecohydrological feedbacks in ecosystem state change in drylands. Ecohydrology. 5, 174-183 (2012).

16. Materials and methods are available as supplementary materials at the Science website.

17. P. M. Groffman et al., Ecological thresholds: the key to successful environmental management or an important concept with no practical application? Ecosystems. 9, 1-13 (2006).

18. S. Whisenant, Repairing Damaged Wildlands: A Process-Orientated, Landscape-Scale Approach (Cambridge University Press, Cambridge, 1999).

19. P. B. Reich, The world-wide "fast-slow" plant economics spectrum: A traits manifesto. $J$. Ecol. 102, 275-301 (2014).

20. V. Maire et al., Global effects of soil and climate on leaf photosynthetic traits and rates. 
Glob. Ecol. Biogeogr. 24, 706-717 (2015).

21. D. E. Carvajal, A. P. Loayza, R. S. Rios, C. A. Delpiano, F. A. Squeo, A hyper arid environment shapes an inverse pattern of the fast-slow plant economics spectrum for above, but not belowground resource acquisition strategies. J. Ecol. 107: 1079-1092 (2019)

22. M. Berdugo et al., Aridity preferences alter the relative importance of abiotic and biotic drivers on plant species abundance in global drylands. J. Ecol. 107, 190-202 (2018).

23. P. D'Odorico, G. S. Okin, B. T. Bestelmeyer, A synthetic review of feedbacks and drivers of shrub encroachment in arid grasslands. Ecohydrology. 5, 520-530 (2012).

24. M. L. Phillips, B. E. McNellis, M. F. Allen, E. B. Allen, Differences in root phenology and water depletion by an invasive grass explains persistence in a Mediterranean ecosystem. Am. J. Bot. 106, 1210-1218 (2019).

25. A. W. R. Seddon, M. Macias-Fauria, P. R. Long, D. Benz, K. J. Willis, Sensitivity of global terrestrial ecosystems to climate variability. Nature. 531, 229 (2016).

26. A. C. Staver, S. Archibald, S. A. Levin, The Global Extent and Determinants of Savanna and Forest as Alternative Biome States. Science 334, 230-232 (2011).

27. S. I. Higgins, S. Scheiter, Atmospheric $\mathrm{CO} 2$ forces abrupt vegetation shifts locally, but not globally. Nature. 488, 209-212 (2012).

28. W. Ulrich et al., Climate and soil attributes determine plant species turnover in global drylands. J. Biogeogr. 41, 2307-2319 (2014).

20 29. Y. Le Bagousse-Pinguet et al., Testing the environmental filtering concept in global drylands. J. Ecol. 105, 1058-1069 (2017). 
30. W. A. Rutherford et al., Albedo feedbacks to future climate via climate change impacts on dryland biocrusts. Sci. Rep. 7, 44188 (2017).

31. H. Wang et al., The China Plant Trait Database: toward a comprehensive regional compilation of functional traits for land plants. Ecology. 99, 500 (2017).

32. D. J. Eldridge, M. Delgado-Baquerizo, S. K. Travers, J. Val, I. Oliver, Do grazing intensity and herbivore type affect soil health? Insights from a semi-arid productivity gradient. $J$. Appl. Ecol. 54, 976-985 (2017).

33. G. Zurlini, K. B. Jones, K. H. Riitters, B. L. Li, I. Petrosillo, Early warning signals of regime shifts from cross-scale connectivity of land-cover patterns. Ecol. Indic. 45, 549-560 (2014).

34. N. J. Middleton, D. S. Thomas, World Atlas of Desertification (United Nations Environment Programme / Edward Arnold, London, 1992; http://www.worldcat.org/isbn/0340555122).

35. M. Delgado-Baquerizo et al., Aridity Decouples C:N:P Stoichiometry Across Multiple Trophic Levels in Terrestrial Ecosystems. Ecosystems 21, 459-468 (2018).

36. C. Wang et al., Aridity threshold in controlling ecosystem nitrogen cycling in arid and semiarid grasslands. Nat. Commun. 5, 4799 (2014).

37. Q. Fu, S. Feng, Responses of terrestrial aridity to global warming. J. Geophys. Res. Atmos. 119, 7863-7875 (2014).

38. R. J. Zomer, A. Trabucco, D. A. Bossio, L. V Verchot, Climate change mitigation: A spatial analysis of global land suitability for clean development mechanism afforestation and reforestation. Agric. Ecosyst. Environ. 126, 67-80 (2008).

39. J. Latham, R. Cumani, I. Rosati, M. Bloise, "FAO Global Land Cover (GLC-SHARE) Beta- 
Release 1.0 Database, Land and Water Division” (Rome, 2014).

40. N. H. Batjes, Harmonized soil property values for broad-scale modelling (WISE30sec) with estimates of global soil carbon stocks. Geoderma 269, 61-68 (2016).

41. W. G. Whitford, Ecology of desert systems (Academic Press, 2002).

42. T. N. Carlson, D. A. Ripley, On the relation between NDVI, fractional vegetation cover, and leaf area index. Remote Sens. Environ. 62, 241-252 (1997).

43. N. Pettorelli et al., Using the satellite-derived NDVI to assess ecological responses to environmental change. Trends Ecol. Evol. 20, 503-510 (2005).

44. C. J. Tucker, C. Vanpraet, E. Boerwinkel, A. Gaston, Satellite remote sensing of total dry matter production in the Senegalese Sahel. Remote Sens. Environ. 13, 461-474 (1983).

45. S. D. Prince, Satellite remote sensing of primary production: comparison of results for Sahelian grasslands 1981-1988. Int. J. Remote Sens. 12, 1301-1311 (1991).

46. K. Didan, MOD13Q1 MODIS/Terra Vegetation Indices 16-Day L3 Global 250m SIN Grid V006 [Dataset]. NASA EOSDIS LP DAAC (2015), doi:10.5067/MODIS/MOD13Q1.006.

15 47. J. G. Masek et al., A Landsat surface reflectance dataset for North America, 1990-2000. IEEE Geosci. Remote Sens. Lett. 3, 68-72 (2006).

48. E. F. Vermote et al., Atmospheric correction of visible to middle-infrared EOS-MODIS data over land surfaces: Background, operational algorithm and validation. J. Geophys. Res. Atmos. 102, 17131-17141 (1997).

20 49. C. O. Justice et al., An overview of MODIS Land data processing and product status. 
Remote Sens. Environ. 83, 3-15 (2002).

50. C. Dimiceli et al., MOD44B MODIS/Terra Vegetation Continuous Fields Yearly L3 Global 250m SIN Grid V006 (NASA EOSDIS Land Processes DAAC, 2015).

51. M. C. Hansen et al., High-Resolution Global Maps of 21st-Century Forest Cover Change. Science 342, 850-853 (2013).

52. A. C. Staver, M. C. Hansen, Analysis of stable states in global savannas: is the CART pulling the horse? - a comment. Glob. Ecol. Biogeogr. 24, 985-987 (2015).

53. N. P. Hanan, A. T. Tredennick, L. Prihodko, G. Bucini, J. Dohn, Analysis of stable states in global savannas: is the CART pulling the horse? Glob. Ecol. Biogeogr. 23, 259-263 (2014).

54. W. Lucht, C. B. Schaaf, A. H. Strahler, An algorithm for the retrieval of albedo from space using semiempirical BRDF models. IEEE Trans. Geosci. Remote Sens. 38, 977-998 (2000).

55. D. Hao et al., Simulation and Analysis of the Topographic Effects on Snow-Free Albedo over Rugged Terrain. Remote Sens. 10, 278 (2018). doi:10.3390/rs10020278.

15 56. T. He, S. Liang, D.-X. Song, Analysis of global land surface albedo climatology and spatial - temporal variation during 1981-2010 from multiple satellite products. J. Geophys. Res. Atmos.,119, 10281-10298 (2014).

57. Y. Zhao et al., Albedo estimated from remote sensing correlates with ecosystem multifunctionality in global drylands. J. Arid Environ. 157, 116-123 (2018).

20 58. J. Liu et al., Validation of Moderate Resolution Imaging Spectroradiometer (MODIS) albedo retrieval algorithm: Dependence of albedo on solar zenith angle. J. Geophys. Res. 
Atmos. 114 (2009), doi:10.1029/2008JD009969.

59. DAAC NASA LP, in USGS Earth Resources Observation and Science (EROS) Center, Sioux Falls, South Dakota (accessed April 14, 2018, at https://lpdaac.usgs.gov/dataset_discovery/modis/modis_products_table/mcd43a1) (2002).

60. H. Q. Liu, A. R. Huete, A feedback based modification of the NDV I to minimize canopy background and atmospheric noise. IEEE Trans. Geosci. Remote Sens. 33, 457-465 (1995).

61. H. von Wehrden, J. Hanspach, K. Ronnenberg, K. Wesche, Inter-annual rainfall variability in Central Asia - A contribution to the discussion on the importance of environmental stochasticity in drylands. J. Arid Environ. 74, 1212-1215 (2010).

62. D. M. S. Smith, N. Abel, B. Walker, F. S. Chapin III, in Principles of ecosystem stewardship (Springer, 2009), pp. 171-195.

63. D. Paolo, B. Abinash, Hydrologic variability in dryland regions: impacts on ecosystem dynamics and food security. Philos. Trans. R. Soc. B Biol. Sci. 367, 3145-3157 (2012).

64. D. N. Karger et al., Climatologies at high resolution for the earth's land surface areas. Sci. Data. 4, 170122 (2017).

65. A. W. Illius, T. G. O'connor, On the relevance of nonequilibrium concepts to arid and semiarid grazing systems. Ecol. Appl. 9, 798-813 (1999).

66. H. von Wehrden, J. Hanspach, P. Kaczensky, J. Fischer, K. Wesche, Global assessment of the non-equilibrium concept in rangelands. Ecol. Appl. 22, 393-399 (2012).

20 67. Millenium Ecosystem Assessment, Ecosystems and Human Well-being: Desertification Synthesis (Island Press Washington, DC, 2005), vol. 5. 
68. U. N. Safriel, Z. Adeel, in Ecosystems and Human Well-being: Current State and Trends. Vol. 1., R. Hassan, R. Scholes, N. Ash, Eds. (Island Press, Washington D.C., USA, 2005), pp. 632-662.

69. F. T. Maestre et al., Plant species richness and ecosystem multifunctionality in global drylands. Science 335, 214-218 (2012).

70. M. Delgado-baquerizo, NSW_Environmental_gradient (2019), doi:10.6084/m9.figshare.7092950.v1.

71. M. Delgado-Baquerizo et al., Palaeoclimate explains a unique proportion of the global variation in soil bacterial communities. Nat. Ecol. Evol. 1, 1339-1347 (2017).

72. M. Delgado-Baquerizo et al., A global atlas of the dominant bacteria found in soil. Science 359, 320-325 (2018).

73. M. Delgado-Baquerizo et al., Microbial diversity drives multifunctionality in terrestrial ecosystems. Nat. Commun. 7, 10541 (2016), doi:10.1038/ncomms10541.

74. J. M. Anderson, J. S. I. Ingram, Tropical soil biology and fertility: A handbook of methods. Soil Sci. 157, 265 (1994).

75. I. Rodriguez-iturbe, A. Porporato, F. Laio, L. Ridolfi, Plants in water-controlled ecosystems : active role in hydrologic processes and response to water stress I . Scope and general outline. Adv. Water Resour. 24, 695-705 (2001).

76. M. Berdugo, S. Soliveres, F. T. F. T. Maestre, Vascular plants and biocrusts modulate how abiotic factors affect wetting and drying events in drylands. Ecosystems. 17, 1242-1256 (2014). 
77. J. G. Ehrenfeld, B. Ravit, K. Elgersma, Feedback in the plant-soil system. Annu. Rev. Environ. Resour. 30, 75-115 (2005).

78. S. Soliveres et al., Microhabitat amelioration and reduced competition among understorey plants as drivers of facilitation across environmental gradients: Towards a unifying framework. Perspect. Plant Ecol. Evol. Syst. 13, 247-258 (2011).

79. S. Kéfi et al., Spatial vegetation patterns and imminent desertification in Mediterranean arid ecosystems. Nature. 449, 213-217 (2007).

80. T. M. Scanlon, K. K. Caylor, S. A. Levin, I. Rodriguez-Iturbe, Positive feedbacks promote power-law clustering of Kalahari vegetation. Nature. 449, 209-212 (2007).

81. S. Peter, B. Elke, Pattern and process: competition causes regular spacing of individuals within plant populations. J. Ecol. 93, 395-403 (2005).

82. H. Saiz, J. Gómez-Gardeñes, J. P. Borda, F. T. Maestre, The structure of plant spatial association networks is linked to plant diversity in global drylands. J. Ecol. 106, 1443-1453 (2018).

15 83. E. Amézketa, Soil Aggregate Stability: A Review. J. Sustain. Agric. 14, 83-151 (1999).

84. W. D. Kemper, R. C. Rosenau, in Methods of Soil Analysis. Part 1. Physical and Mineralogical Properties, Including Statistics of Measurement and Sampling., E. A. Klute, Ed. (American Society of Agronomy- Soil Science of America, Madison (USA), 1986), pp. $425-442$.

85. F. T. Maestre et al., Increasing aridity reduces soil microbial diversity and abundance in global drylands. Proc. Natl. Acad. Sci. 112, 15684-15689 (2015). 
86. J. G. Caporaso et al., Ultra-high-throughput microbial community analysis on the Illumina HiSeq and MiSeq platforms. Isme J. 6, 1621 (2012).

87. D. P. R. Herlemann et al., Transitions in bacterial communities along the $2000 \mathrm{~km}$ salinity gradient of the Baltic Sea. Isme J. 5, 1571 (2011).

88. K. Ihrmark et al., New primers to amplify the fungal ITS2 region - evaluation by 454sequencing of artificial and natural communities. FEMS Microbiol. Ecol. 82, 666-677 (2012).

89. R. C. Edgar, UPARSE: highly accurate OTU sequences from microbial amplicon reads. Nat. Methods. 10, 996 (2013).

90. P. D. Schloss et al., Introducing mothur: Open-Source, Platform-Independent, CommunitySupported Software for Describing and Comparing Microbial Communities. Appl. Environ. Microbiol., 75, 7537-7541 (2009).

91. U. Kõljalg et al., Towards a unified paradigm for sequence-based identification of fungi. Mol. Ecol. 22, 5271-5277 (2013).

15 92. N. H. Nguyen et al., FUNGuild: An open annotation tool for parsing fungal community datasets by ecological guild. Fungal Ecol. 20, 241-248 (2016).

93. D. J. Eldridge, M. Delgado-Baquerizo, Functional groups of soil fungi decline under grazing. Plant Soil. 426, 51-60 (2018).

94. P. García-Palacios, N. Gross, J. Gaitán, F. T. Maestre, Climate mediates the biodiversityecosystem stability relationship globally. Proc. Natl. Acad. Sci. 115, 8400-8405 (2018).

95. J. H. C. Cornelissen et al., A handbook of protocols for standardised and easy measurement 
of plant functional traits worldwide. Aust. J. Bot. 51, 335-380 (2003).

96. Y.-J. Zhang, L. Sack, K.-F. Cao, X.-M. Wei, N. Li, Speed versus endurance tradeoff in plants: Leaves with higher photosynthetic rates show stronger seasonal declines. Sci. Rep. 7, 42085 (2017).

97. S. M. Gleason, D. W. Butler, P. Waryszak, Shifts in Leaf and Stem Hydraulic Traits across Aridity Gradients in Eastern Australia. Int. J. Plant Sci. 174, 1292-1301 (2013).

98. A. Nunes et al., Which plant traits respond to aridity? A critical step to assess functional diversity in Mediterranean drylands. Agric. For. Meteorol. 239, 176-184 (2017)

99. N. Gross et al., Uncovering multiscale effects of aridity and biotic interactions on the functional structure of Mediterranean shrublands. J. Ecol. 101, 637-649 (2013).

100. S. Lavorel, E. Garnier, Predicting changes in community composition and ecosystem functioning from plant traits: revisiting the Holy Grail. Funct. Ecol. 16, 545-556 (2002).

101. P. Liu, J. Huang, O. J. Sun, X. Han, Litter decomposition and nutrient release as affected by soil nitrogen availability and litter quality in a semiarid grassland ecosystem. Oecologia. 162, 771-80 (2010).

102. S. Manzoni, R. B. Jackson, J. A. Trofymow, A. Porporato, The Global Stoichiometry of Litter Nitrogen Mineralization. Science 328, 684-686 (2008).

103. T. Hastie, gam: Generalized Additive Models (2017), (available at https://cran.rproject.org/package= gam $)$

104. H. Akaike, A new look at the statistical model identification. IEEE Trans. Automat. Contr. 19, 716-723 (1974). 
105. V. M. R. Muggeo, segmented: an R Package to Fit Regression Models with Broken-Line Relationships. R News. 8, 20-25 (2008).

106. Y. Fong, Y. Huang, P. Gilbert, S. Permar, chngpt: threshold regression model estimation and inference. BMC Bioinformatics 18, 454. doi: 10.1186/s12859-017-1863-x (2017).

107. R. Pastor-Barriuso, E. Guallar, J. Coresh, Transition models for change-point estimation in logistic regression. Stat. Med. 22, 1141-1162 (2002).

108. M. Scheffer, M. Hirota, M. Holmgren, E. H. Van Nes, F. S. Chapin, Thresholds for boreal biome transitions. Proc. Natl. Acad. Sci. 109, 21384-21389 (2012).

109. V. N. Livina, T. M. Lenton, A modified method for detecting incipient bifurcations in a dynamical system. Geophys. Res. Lett. 34 (2007), doi:10.1029/2006GL028672.

110. M. Hirota, M. Holmgren, E. H. Van Nes, M. Scheffer, Global resilience of tropical forest and savanna to critical transitions. Science 334, 232-235 (2011).

111. B. S. Cade, B. R. Noon, A gentle introduction to quantile regression for ecologists. Front. Ecol. Environ. 1, 412-420 (2003).

15 112. P. Fearnhead, G. Rigaill, Changepoint Detection in the Presence of Outliers. J. Am. Stat. Assoc. 114, 1-15 (2017).

113. J. Fan, F. Han, H. Liu, Challenges of Big Data analysis. Natl. Sci. Rev. 1, 293-314 (2014).

114. R Development Core Team, R: A Language and Environment for Statistical Computing (2008), (available at http://www.r-project.org).

20 115. C. Goutte, P. Toft, E. Rostrup, F. Å. Nielsen, L. K. Hansen, On Clustering fMRI Time 
Series. Neuroimage. 9, 298-310 (1999).

116. T. F. Stocker et al., Climate change 2013: the physical science basis. Contribution of working group I to the fifth assessment report of the intergovernmental panel on climate change (Cambridge University Press, Geneva, 2013).

117. S. T. A. Pickett, in Long Term Studies in Ecology, G. E. Lickens, Ed. (Springer, New York, New York, 1989), pp. 110-135.

118. M. Delgado-Baquerizo et al., Human impacts and aridity differentially alter soil $\mathrm{N}$ availability in drylands worldwide. Glob. Ecol. Biogeogr. 25, 36-45 (2016).

119. L. R. Walker, D. A. Wardle, R. D. Bardgett, B. D. Clarkson, The use of chronosequences in studies of ecological succession and soil development. J. Ecol. 98, 725-736 (2010).

120. E. D. Schulze et al., Rooting depth, water availability, and vegetation cover along an aridity gradient in Patagonia. Oecologia. 108, 503-511 (1996).

121. J. L. Blois, J. W. Williams, M. C. Fitzpatrick, S. T. Jackson, S. Ferrier, Space can substitute for time in predicting climate-change effects on biodiversity. Proc. Natl. Acad. Sci. 110, 9374-9379 (2013).

122. C. Damgaard, A Critique of the Space-for-Time Substitution Practice in Community Ecology. Trends Ecol. Evol. 34, 416-421 (2019).

123. E. A. Johnson, K. Miyanishi, Testing the assumptions of chronosequences in succession. Ecol. Lett. 11, 419-431 (2008).

124. M. Berdugo, M. Delgado-Baquerizo, S. Soliveres, R. Hernández-Clemente, Y. Zhao, J. J. Gaitán, N. Gross, H. Saiz, V. Maire, A. Lehman, M. C. Rillig, R. V. Solé F. T. Maestre. 
Data and code used in the article: Global ecosystem thresholds driven by aridity. figshare (2019). doi: 10.6084/m9.figshare.7813886 